\title{
Morphologic Change of Flow-Related Aneurysms in Brain Arteriovenous Malformations after Stereotactic Radiosurgery
}

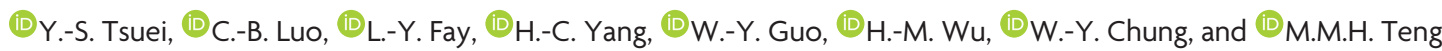

\begin{abstract}
BACKGROUND AND PURPOSE: The natural history of flow-related aneurysms after obliteration of brain arteriovenous malformations is poorly understood. The purpose of this study was to evaluate the angioarchitecture and morphologic change in flow-related aneurysms after gamma knife surgery of brain arteriovenous malformations.
\end{abstract}

MATERIALS AND METHODS: During a 12-year period, 823 patients with brain arteriovenous malformations underwent gamma knife surgery at our institution with complete peritherapeutic angiographic evaluation. From this population, a series of 72 patients (8.8\%) with 111 flow-related aneurysms were enrolled (1.5 aneurysms per patient). There were 43 men and 29 women; ages ranged from 18 to 72 years (mean, 43 years). The morphologic change of flow-related aneurysms was longitudinally evaluated before and after obliteration of brain arteriovenous malformations. After gamma knife surgery, angiographic follow-up varied from 26 to 130 months (mean, 58 months).

RESULTS: All flow-related aneurysms were small (mean, $4.1 \mathrm{~mm}$; range, 2-9 mm). There were 72 proximal flow-related aneurysms (mean size, $4.3 \mathrm{~mm}$ ) and 39 distal flow-related aneurysms (mean size, $3.7 \mathrm{~mm}$ ). Spontaneous thrombosis occurred more frequently in distal flow-related aneurysms than in proximal flow-related aneurysms $(P<.001)$. Smaller flow-related aneurysms $(<5 \mathrm{~mm})$ tended to spontaneously occlude after obliteration of brain arteriovenous malformations $(P=.036)$. Two patients had ruptures of proximal flow-related aneurysms at 27- and 54-month follow-ups, respectively.

CONCLUSIONS: Spontaneous thrombosis occurred more frequently in distal flow-related aneurysms due to occlusion or normalization of distal feeders. Smaller flow-related aneurysms also tended to spontaneously thrombose after obliteration of brain arteriovenous malformations. The rate of flow-related aneurysm rupture in our series was similar to that of natural intradural aneurysms.

ABBREVIATIONS: $\mathrm{ACA}=$ anterior cerebral artery; $\mathrm{BAVM}=$ brain arteriovenous malformation; $\mathrm{FA}=$ flow-related aneurysm; $\mathrm{GKS}=$ gamma knife surgery

$\mathrm{T}$ he association between brain arteriovenous malformations (BAVMs) and flow-related aneurysms (FAs) is well-documented in the literature. The risk of hemorrhage is reported to be $7 \%-10 \%$ annually in patients with concomitant BAVMs and intradural aneurysms, and it is higher in patients with concomitant BAVMs than in patients with only BAVMs. ${ }^{1,2}$ Current management of FAs of BAVMs is controversial because of the inherent risk associated with aggressive interventional management and

Received May 26, 2018; accepted after revision January 25, 2019.

From the Department of Neurosurgery (Y.-S.T.), Taichung Veterans General Hospital, Taichung, Taiwan; Departments of Neurosugery (Y.-S.T.) and Radiology (C.-B.L.), Tri-Service General Hospital, National Defenses Medical Center, Taipei, Taiwan; Departments of Radiology (C.-B.L., W.-Y.G., H.-M.W., M.M.H.T.) and Neurosurgery (L.-Y.F., H.-C.Y., W.-Y.C.), Taipei Veterans General Hospital and National Yang-Ming University, School of Medicine, Taipei, Taiwan; and Department of Radiology (M.M.H.T.), Cheng-Hsin General Hospital, Taipei, Taiwan.

Please address correspondence to Chao-Bao Luo, MD, Department of Radiology, Taipei Veterans General Hospital, 201, Section 2, Shih-Pai Rd, Taipei 112, Taiwan, ROC; e-mail: cbluo@vghtpe.gov.tw

http://dx.doi.org/10.3174/ajnr.A6018 the unclear natural course of FAs. Some authors propose that symptomatic BAVMs should be the primary treatment target, with FAs left to observation because of the possibility that they can spontaneously occlude after an alteration in hemodynamics following BAVM obliteration. ${ }^{3}$ On the other hand, some authors claim that FAs should be actively treated at the time of BAVM management because FAs are a critical risk factor for intracranial hemorrhage. ${ }^{4-8}$ The natural history of FAs after BAVM obliteration by stereotactic gamma knife surgery (GKS) remains unclear. Understanding the morphologic change of FAs during the latency period after stereotactic GKS would greatly impact the FA management strategy. The purpose of this study was to longitudinally evaluate changes in FA morphology after hemodynamic alterations produced by BAVM obliteration.

\section{MATERIALS AND METHODS Patient Demographics}

From September 1994 to August 2015, a total of 936 patients with BAVMs were referred to Taipei Veterans General Hospital to de- 
Table 1: Demographics of patients with BAVMs enrolled and characteristics of FAs

\begin{tabular}{lc}
\hline & Value \\
\hline No. of eligible patients & 936 \\
No. of excluded patients & 113 \\
No. of patients with <50\% obliteration & 39 \\
$\quad$ of BAVM & \\
No. of patients without DSA follow-up & 57 \\
No. of interventions of FAs & 17 \\
No. of patients enrolled & 823 \\
No. of patients with FAs enrolled & $72(8.8 \%)$ \\
Mean age (yr) & $43($ range, $18-72)$ \\
Sex (No.) & \\
Female & $29(40 \%)$ \\
Male & $43(60 \%)$ \\
No., location, and size of FAs (mm) & \\
Total No. of FAs (mean size) & $111(4.1)$ \\
Mean size of proximal FAs & 4.3 \\
Mean size of distal FA & 3.7 \\
No. of FAs per patient & 1.5 \\
No. of FAs in supratentorium & 98 \\
No. of FAs in ICA & 42 \\
No. of FAs in proximal/distal MCA & $16 / 14$ \\
No. of FAs in proximal/distal ACA & $9 / 17$ \\
No. of FAs in infratntorium & 13 \\
No. of proximal FAs & 5 \\
No. of distal FAs & 8 \\
\hline
\end{tabular}

termine the feasibility of GKS. One hundred thirteen patients were excluded because of incomplete follow-up by DSA $(n=57)$, insufficient hemodynamic alteration by obliteration of $<50 \%$ of the BAVM $(n=39)$, and interventional management of the FA $(n=17)$. A series of 823 patients with $>24$ months of DSA follow-up after GKS were enrolled (Table 1). Before GKS, the patients underwent 4-vessel cerebral DSA to evaluate the BAVM angioarchitecture (including location/size of the BAVM), the association of intranidal aneurysms with flow-related aneurysms, and the coexistence of a high-flow arteriovenous fistula and venous outflow. 3D reconstruction of rotational DSA, which has been part of the standard protocol for angioarchitectural analysis of BAVM since 2002, was performed to evaluate the angioarchitecture of BAVMs and to search for FAs. Therefore, a total of 346 patients (42\%) did not have 3D reconstruction of rotational DSA. The absence of this modern protocol may lead to underestimation of the real incidence of FAs in our series.

GKS was performed once in 689 patients; it was repeated a second ( $n=106)$ or third $(n=28)$ time in 134 patients because of residual BAVMs. After GKS, patients were followed up for progression and obliteration of BAVMs by MR imaging and MRA every 3-6 months. DSA was performed when the MRA showed partial regression or total occlusion of BAVMs 3 years after GKS to check the angioarchitecture. This study was approved by the ethics committee of the institution in 2014.

\section{Angiographic Analyses}

FA was defined as an arterial pouch in the feeders of BAVMs; the size of the aneurysms in this study was at least $2 \mathrm{~mm}$. FAs were grouped by the size of their maximal dimension into small $(<5$ $\mathrm{mm}$ ) and large (at least $5 \mathrm{~mm}$ ); by distribution of FAs into ICA, anterior cerebral artery (ACA), and MCA as well as infratentorium; and by location into proximal and distal FAs based on Re- dekop et $\mathrm{al}^{2}$ FAs in the supraclinoid ICA, M1 segment of the MCA, A1 segment of the ACA, anterior communicating artery, basilar artery, and $\mathrm{P} 1$ of posterior cerebral artery were considered proximal, while those located beyond this territory were considered distal. FAs were also classified by morphologic change into enlargement, stable, and partial or complete regression. These angiographic decisions were made by 2 experienced interventional neuroradiologists (C.-B.L. and Y.-S.T.) independently, using the same workstation. Any discrepancy in the angiographic findings of these 2 interventional neuroradiologists was resolved through reassessment and discussion of the DSA.

\section{Statistical Analyses}

The differences in continuous variables (ie, mean age of patients, mean volume of BAVM, and mean size of FA) between stable and regressive FAs were compared by means of an independent-samples $t$ test. The differences in categoric variables (ie, sex, ruptured/ unruptured BAVMs, and complete/incomplete obliteration of the BAVM as well as location/size of the FAs) between stable and regressive FAs were compared using the Fisher exact test. Data analyses were performed using SPSS 22 (IBM, Armonk, New York). A 2 -sided $P$ value $<.05$ was considered statistically significant. No adjustment of multiple testing (multiplicity) was made in this study.

\section{RESULTS}

\section{Overall Findings}

A total of 72 patients $(8.8 \% ; 43$ men and 29 women; mean age, 43 years; range, $18-72$ years) with 111 FAs (1.5 FAs per patient) were enrolled in this study and had complete DSA follow-up after partial $(n=11,50 \%-80 \%)$, subtotal $(n=9,>80 \%)$, or total obliteration ( $n=52$ ) of BAVMs by GKS. The major clinical manifestations were headache $(n=39)$, seizure $(n=23)$, and neurologic deficits $(n=29)$. Ruptured BAVMs with intracranial hemorrhage were found in 31 patients, while unruptured BAVMs were found in 41. Post-GK DSA follow-up varied from 26 to 130 months (mean, 58 months).

\section{Angioarchitecture of FAs}

The location and size of 111 FAs are summarized in Table 1. The number of patients with 1, 2, 3, and $>3$ FAs was 46 (Fig 1), 16 (Figs 2 and 3), 7, and 3. Multiple FAs were found in 26 of 72 patients (36\%). The size of the FAs varied from 2 to $9 \mathrm{~mm}$ (mean, $4.1 \mathrm{~mm}$ ). The locations of the FAs were the ICA in 42 patients, MCA in 30, ACA in 26, and infratentorium in 13. Seventy-two were proximal FAs with a mean size of $4.3 \mathrm{~mm}$, and 39 were distal FAs with a mean size $3.7 \mathrm{~mm}$. Ninety-nine (89\%) FAs were small $(<5 \mathrm{~mm})$; the other $12(11 \%)$ were at least $5 \mathrm{~mm}$.

Morphologic Change and Natural Course of FAs after GKS Of the $111 \mathrm{FAs}, 60$ (54\%) showed stable size, 25 (23\%) showed partial size regression, and 26 (23\%) showed total obliteration. In 51 FAs with size regression, 11 demonstrated total occlusion of distal feeders, while 40 trended toward normalization of features of the parent arteries. No instance of enlargement of FAs was found in a mean 58-month period of DSA follow-up. In terms of regressive FAs during follow-up, there was no statistical signifi- 


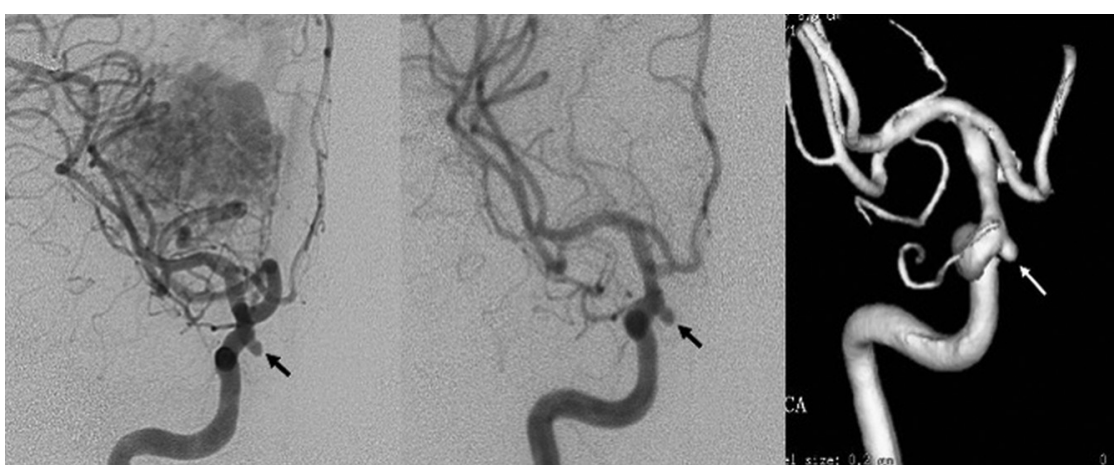

FIG 1. Left, The patient had a right parieto-occipital brain arteriovenous malformation with a small flow-related aneurysm (arrow) at the right medial paraclinoid internal carotid artery. Right, Conventional angiography at 54 months after stereotactic gamma knife surgery demonstrates almost total obliteration of the BAVM but no obvious morphologic change in the proximal FA.

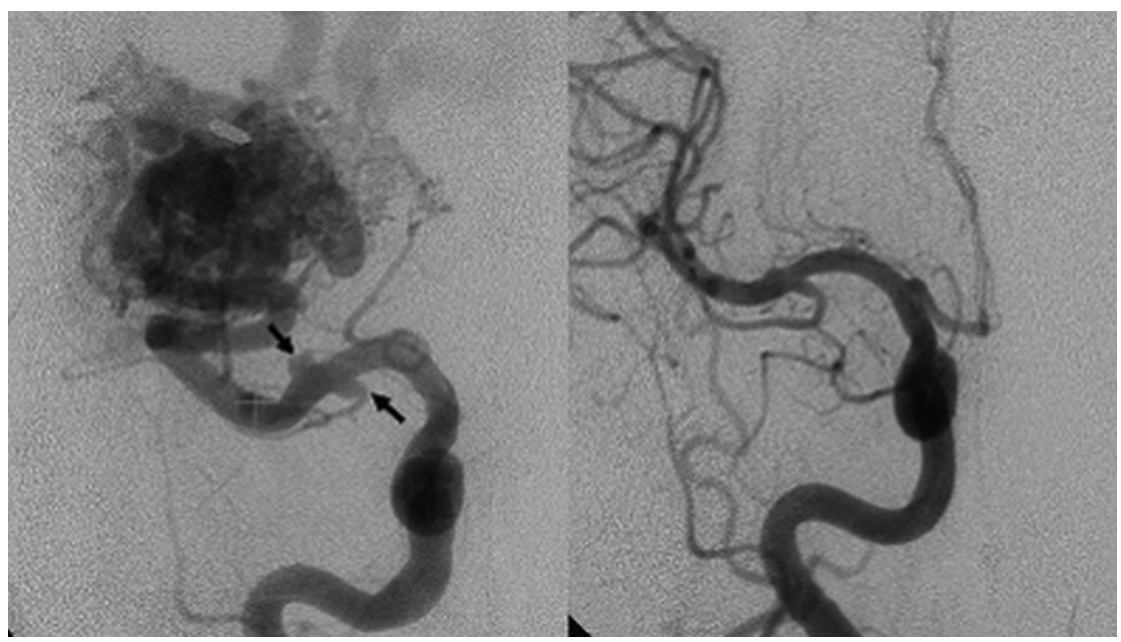

FIG 2. Left, The patient had a right frontotemporal BAVM and small proximal FAs at the M1 segment of the right middle cerebral artery (arrows). Right, Conventional angiography at 38 months after GKS demonstrates almost total regression of the proximal FAs.

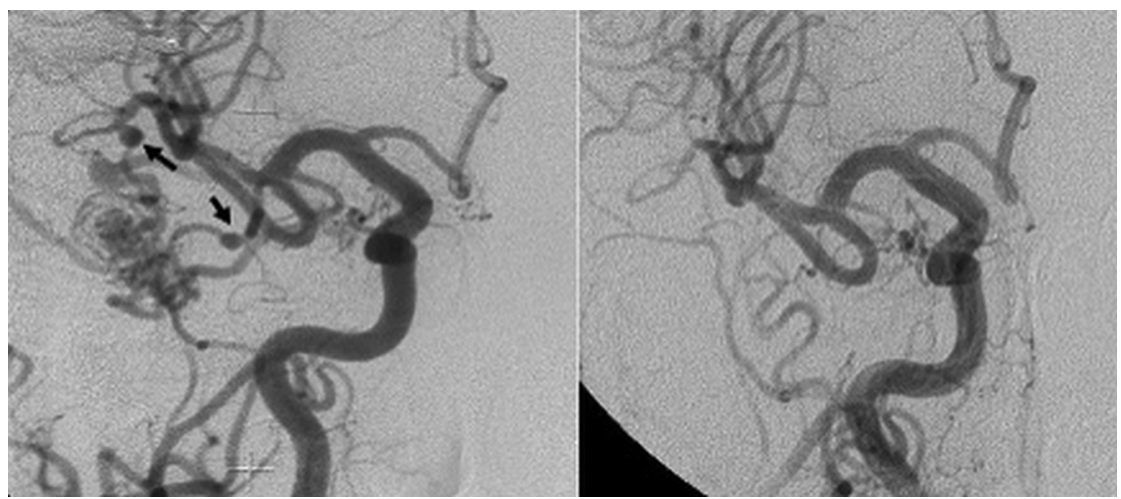

FIG 3. Left, The patient had a right inferior temporal BAVM and 2 distal FAs at the $M 2$ segment of the right middle cerebral artery (arrows). Right, Conventional angiography at 37 months after GKS demonstrates total obliteration of the distal FAs with normalization of blood flow through the feeders to the BAVM and FAs.

cance in sex $(P=.70)$, patient age $(P=.21)$, ruptured/unruptured BAVMs $(P=.85)$, or complete/incomplete obliteration of BAVMs $(P=.286)$, but FA regression demonstrated statistical significance in the volume of BAVMs $(P=.048)$ and size of FAs $(P=.0001)$ (Table 2). The rate of partial or complete obliteration was statistically significantly lower in proximal-versus-distal FAs
$(P<.001$, Table 3); proximal-versusdistal FAs of the MCA showed statistical significance $(38 \%$ versus $86 \% ; P=.01$ ). However, proximal-versus-distal FA regression was not significant in the ACA territory ( $44 \%$ versus $76 \%, P=.19$ ) and in those proximal-versus-distal FAs of the infratentorium (25\% versus $89 \%$; $P=.052)$. Partial or complete obliteration was found in 49 of 99 FAs of $<5 \mathrm{~mm}$ (49\%). FAs of $<5 \mathrm{~mm}$ (in contrast to larger FAs) had a slightly greater tendency to regress in size $(49 \%$ versus $17 \%, P=.04$, Table 4 ), but the difference in regression between the 2 groups in individual territories of the MCA (64\% versus $40 \%, P=.364)$, ICA (19\% versus $0 \%, P=.57)$, and infratentorium (75\% versus $0 \%, P=.31$ ) was not statistically significant (Table 4). Two patients had ruptured proximal FAs (basilar tip and ICA) in the 27th and 54th months of clinical follow-up, respectively, and 1 rupture was associated with a fatal SAH.

\section{DISCUSSION}

The exact mechanism of FA formation in BAVMs is not fully understood. Increased blood flow stress of the BAVM is presumed to be a major factor undoing the balance between hemodynamic stress and the integrity of the internal elastic lamina and intima of the arterial wall. Rapid or turbulent blood flow in the feeders of BAVMs is also reported to be a more important hemodynamic factor in FA formation than intravascular pressure. $^{2}$ Previous studies had shown that older patients with larger BAVMs and posterior circulation supply to the BAVM are prone to FAs. ${ }^{9,10}$ The reported incidence of FAs ranges from $6 \%$ to $27 \% .^{4,9,10-16}$ This variation of the incidence of FAs may be attributed to different criteria of FA and DSA protocols, overlooked small FAs, and a lack of superselective microcatheterization of cerebral arteries. ${ }^{17}$ In the past, conventional 2D-DSA was the criterion standard method of evaluating BAVM angioarchitecture. Nevertheless, because of the overlap of FAs by the parent artery or arterial branch on conventional DSA and the lack of rotational and 3D-reconstruction DSA, 2D-DSA may overlook $6.8 \%-21 \%$ of intracranial aneurysms, particularly, aneurysms of $<3 \mathrm{~mm}^{18-21}$

In our series, the incidence of FAs was $8.8 \%$; this was within 
Table 2. Demographics of 111 FAs in 72 patients with BAVMs after radiosurgery ${ }^{\mathrm{a}}$

\begin{tabular}{|c|c|c|c|}
\hline Parameters & $\begin{array}{c}\text { Stable } \\
\text { FAs } \\
(n=60)\end{array}$ & $\begin{array}{l}\text { Regressive } \\
\text { FAs }(n=51)\end{array}$ & $\begin{array}{c}P \\
\text { Value }\end{array}$ \\
\hline Sex & & & .70 \\
\hline Male $(n=43)$ & $35(57)$ & $27(44)$ & \\
\hline Female $(n=29)$ & $25(51)$ & $24(49)$ & \\
\hline Mean age of patients (yr) & $41 \pm 10$ & $44 \pm 15$ & .21 \\
\hline Mean volume of BAVM $(\mathrm{mL})$ & $36 \pm 9$ & $40 \pm 12$ & $.048^{\mathrm{b}}$ \\
\hline Mean size of FAs (mm) & $4.5 \pm 0.9$ & $3.6 \pm 0.5$ & $.0001^{\mathrm{b}}$ \\
\hline $\begin{array}{l}\text { No. of ruptured/unruptured } \\
\text { BAVMs }\end{array}$ & & & .85 \\
\hline Ruptured $(n=31)$ & $26(55)$ & $21(45)$ & \\
\hline Unruptured $(n=41)$ & $34(53)$ & $30(47)$ & \\
\hline $\begin{array}{c}\text { No. of complete/incomplete } \\
\text { obliteration of BAVMs }\end{array}$ & & & .29 \\
\hline Complete $(n=52)$ & $41(51)$ & $40(49)$ & \\
\hline Incomplete $(n=20)$ & $19(63)$ & $11(37)$ & \\
\hline
\end{tabular}

Table 3: Location and morphologic change of FAs of BAVMs ${ }^{\mathrm{a}}$

\begin{tabular}{ccccc}
\hline & $\begin{array}{c}\text { No. } \\
\text { of }\end{array}$ & $\begin{array}{c}\text { No. of } \\
\text { Stable }\end{array}$ & $\begin{array}{c}\text { No. of } \\
\text { Regressive } \\
\text { FAs/Total } \\
\text { Regression }\end{array}$ & $\begin{array}{c}P \text { Value of } \\
\text { Regression in } \\
\text { Proximal and } \\
\text { Distal FAs }\end{array}$ \\
\hline Supratentorium & 98 & $56(57)$ & $42(43) / 20(20)$ & \\
ACA & 26 & & & \\
Proximal (\%) & 9 & $5(56)$ & $4(44) / 1(11)$ & .19 \\
Distal (\%) & 17 & $4(24)$ & $13(76) / 8(47)$ & \\
MCA & 30 & & & \\
Proximal (\%) & 16 & $10(63)$ & $6(38) / 2(13)$ & .01 \\
Distal (\%) & 14 & $2(14)$ & $12(86) / 9(62)$ & \\
ICA (proximal) & 42 & $35(83)$ & $7(17) / 0(0)$ & NA \\
Infratentorium & 13 & & & \\
Proximal & 4 & $3(75)$ & $1(25) / 1(25)$ & .052 \\
Distal & 9 & $1(11)$ & $8(89) / 5(56)$ & \\
Overall & 111 & $60(54)$ & $51(46) / 26(23)$ & \\
Proximal (\%) & 71 & $53(75)$ & $18(25) / 4(6)$ & $<.001^{\mathrm{b}}$ \\
Distal (\%) & 40 & $7(18)$ & $33(83) / 22(55)$ & \\
\hline
\end{tabular}

Note:-NA indicates not available.

${ }^{a}$ Data in parentheses are percentages. Numbers in parentheses do not add up to $100 \%$ due to rounding.

${ }^{\mathrm{b}} \mathrm{P}<.05$, indicates statistical significance.

the range of previously reported rates but slightly lower than the average detection rate. The lower detection rate was likely due to the lack of superselective microcatheter DSA in all patients and the absence of rotational/reconstruction DSA in $42 \%$ of patients in our series. Multiple FAs were found in 26 of 72 patients (36\%); the number of FAs per patient was 1.5. The frequency of multiple FAs in our series was compatible with that in the series of Redekop et $\mathrm{al}^{2}$ in which 123 FAs occurred in 71 patients, but it was much higher than that in the series of Morgan et al $^{9}$ with 4 of 67 patients $(6 \%)$ with multiple FAs. Most FAs are small and $<8 \mathrm{~mm}^{4,8,9,22}$ In our series, all FAs were small (mean size, $4.1 \mathrm{~mm}$ ), with proximal FAs (mean size, $4.3 \mathrm{~mm}$ ) being a little larger than distal FAs (mean size, $3.7 \mathrm{~mm}$ ). However, in recently published data of 172 hemodynamic saccular aneurysms of BAVMs, ${ }^{8} 62 \%$ of aneurysms were $<6 \mathrm{~mm}$, but $38 \%$ of aneurysms were $>7 \mathrm{~mm}$, with $17 \%$ of aneurysms $>16 \mathrm{~mm}$. This result may be attributed to the coincidence of natural intracranial aneurysms with BAVMs.

The annual growth rate of most natural unruptured intracra-
Table 4: Size and morphologic change of FAs of BAVMs ${ }^{a}$

\begin{tabular}{|c|c|c|c|c|}
\hline Location of FA & $\begin{array}{l}\text { No. } \\
\text { of } \\
\text { FAs }\end{array}$ & $\begin{array}{l}\text { No. of } \\
\text { Stable } \\
\text { FAs }\end{array}$ & $\begin{array}{c}\text { No. of } \\
\text { Regressive } \\
\text { FAs/Total } \\
\text { Regression }\end{array}$ & $\begin{array}{c}P \text { Value of } \\
\text { Regression in } \\
\text { Small FAs } \\
(<5 \mathrm{~mm})\end{array}$ \\
\hline Supratentorium & 98 & $56(57)$ & $42(43) / 20(20)$ & \\
\hline$A C A$ & 26 & & & \\
\hline$<5 \mathrm{~mm}(\%)$ & 26 & $9(35)$ & $17(65) / 13(50)$ & NA \\
\hline$\geq 5 \mathrm{~mm}(\%)$ & 0 & $0(0)^{\prime}$ & $0(0)$ & \\
\hline MCA & 30 & & & \\
\hline$<5 \mathrm{~mm}(\%)$ & 25 & $9(36)$ & $16(64) / 9(36)$ & .36 \\
\hline$\geq 5 \mathrm{~mm}(\%)$ & 5 & $3(60)$ & $2(40) / 0(0)$ & \\
\hline ICA & 42 & & & \\
\hline$<5 \mathrm{~mm}(\%)$ & 36 & $29(80)$ & $7(19) / 0(0)$ & .57 \\
\hline$\geq 5$ mm (\%) & 6 & $6(100)$ & $0(0)$ & \\
\hline Infratentorium & 13 & $3(25)$ & $9(75) / 2(17)$ & .31 \\
\hline$<5 \mathrm{~mm}(\%)$ & 12 & & & \\
\hline$\geq 5 \mathrm{~mm}(\%)$ & 1 & $1(100)$ & $0(0)$ & \\
\hline Overall & 111 & $60(54)$ & $51(46) / 26(23)$ & $.036^{\mathrm{b}}$ \\
\hline$<5 \mathrm{~mm}(\%)$ & 99 & $50(51)$ & $49(49) / 26(26)$ & \\
\hline$\geq 5 \mathrm{~mm}(\%)$ & 12 & $10(83)$ & $2(17) / 0(0)$ & \\
\hline
\end{tabular}

${ }^{a}$ Data in parentheses are percentages. Numbers in parentheses do not add up to $100 \%$ due to rounding.

${ }^{b} P<.05$, indicates statistical significance.

nial aneurysms is highly variable and unpredictable. ${ }^{15}$ Spontaneous partial or complete thrombosis is uncommon in intracranial aneurysms. ${ }^{23}$ FAs can be differentiated from natural unruptured intracranial aneurysms because they are impacted by the hemodynamic stress of BAVMs, and the latter are not. In our series, FAs tended to be regressive in larger BAVMs $(P=.048)$ and smaller FAs $(P=.0001)$ during follow-up and showed statistical significance, but there was no statistical significance in sex $(P=.70)$, patient age $(P=.21)$, ruptured/unruptured BAVMs $(P=.85)$, or complete/incomplete obliteration of BAVMs $(P=.29)$. Larger BAVM obliteration was usually associated with greater alteration of hemodynamics, leading to size regression of FAs. Smaller FAs were more commonly found in distal FAs than proximal FAs. Redekop et $\mathrm{al}^{2}$ reported the tendency of distal FAs to spontaneously disappear after complete BAVM occlusion, which occurred in 4 of 5 FAs $(80 \%)$ in their series, whereas only $21.7 \%$ (23 of 106 proximal FAs) decreased in size after BAVM treatment. This result was similar to our results with statistical significance $(P<$ $.001)$ : Thirty-three of 40 (83\%) distal FAs partially or totally disappeared, but only 18 of 71 (25\%) proximal FAs regressed in size or totally disappeared. In terms of the individual territory of size regression of distal-versus-proximal FAs, the MCA territory showed statistical significance $(P=.01)$, but the territories of the ACA and infratentorium were not statistically significant $(P=$ $.19, P=.052)$.

Spontaneous thrombosis of a distal FA tends to occur largely because most distal feeders provide blood to the BAVM, where total BAVM obliteration usually leads to total occlusion and significant reduction of the caliber of the distal feeder and thereby to total or partial regression of the FA. By contrast, the parent artery of proximal FAs supplies both normal brain tissue and the BAVM, where total or subtotal occlusion of the BAVM normalizes the blood flow of the parent artery, reducing the hemodynamic stress on feeders; however, the hemodynamic flow from the normal parent artery to the proximal FA persists, reducing the frequency of spontaneous thrombosis of proximal FAs to less than that of 
distal FAs. Although small-sized FAs tended to disappear after integration of the data of all territories $(P=.04)$, the frequency of FA regression was not statistically significantly related to FA size in individual territories of the MCA $(P=.36)$, ICA $(P=.57)$, and infratentorium $(P=.31)$. In our study, there was no significant enlargement of FA size at a mean 58-month DSA follow-up.

Stereotactic radiosurgery has been widely used to manage patients with BAVMs with promising results. The reported cure rate for BAVMs at 3 years after stereotactic radiosurgery may be as high as $56 \%-85 \%$ in some selected patients. ${ }^{6,24}$ In terms of peritherapeutic hemodynamic change, GKS differs from endovascular embolization and surgical removal by obliterating BAVMs gradually and slowly so that the hemodynamic impact on brain tissue and FAs is progressively decreased with less risk of an acute sudden increase in the transmural pressure across the dome of the FA, leading to rupture. Previous studies had shown that the presence of an associated aneurysm significantly increases the risk of rehemorrhaging after stereotactic radiosurgery. ${ }^{6}$ FAs are an independent determinant for increased risk of incident BAVM hemorrhage $^{21}$, and FAs may change the natural course of BAVM with increasing hemorrhage. ${ }^{9}$ These findings suggest the need for additional interventional management of the aneurysm to reduce the risk of bleeding during the latency interval after stereotactic radiosurgery for BAVMs. ${ }^{6,7}$ However, in our 72 patients with 111 FAs and an average of 58 months of angiographic and clinical follow-up, only 2 patients developed a ruptured FA; 1 rupture had fatal consequences. The rupture rate per aneurysm/year was calculated to be $0.37 \%$, and the incidence of FA rupture was similar to that reported for natural unruptured intradural aneurysms. ${ }^{25,26}$

Aggressive management of FAs has been reported with promising results. ${ }^{8}$ For distal FAs that usually have a wide neck or fusiform dilation, it is feasible in some selected patients to perform embolization with liquid embolic materials to obliterate the BAVMs and distal FAs in the same session. ${ }^{4}$ For small smoothcontoured proximal FAs with a relatively low risk of rupture, conservative management is an acceptable option. Nevertheless, with ruptured or symptomatic FAs, proximal FAs larger than $5 \mathrm{~mm}$, irregularly shaped FAs, and those patients with a family history of a ruptured aneurysm, aggressive management by interventional procedures is indicated. Because most proximal FAs are widenecked, stent-assisted coiling may be necessary to prevent coil migration to the parent artery; however, this technique should be used with caution because of the need for peritherapeutic antiplatelet medication to prevent stent-related thromboembolic complications. Antiplatelet treatment will worsen bleeding from ruptured or reruptured BAVMs or residual BAVMs. The technique of balloon-assisted FA coiling is an alternative. It is better to perform stent-assisted coil embolization and endovascular management of BAVMs during the same session to totally eliminate the risk of bleeding or rebleeding (eg, bleeding from an intranidal aneurysm) rather than wait for total obliteration of the BAVM. In our series, most FAs were small (mean size, $4.1 \mathrm{~mm}$ ). Considering the natural course of small, unruptured FAs, most of our FAs were conservatively managed by neuroimaging follow-up.

There were some limitations to our study: First, this is a retrospective study of long duration. A prospective study is warranted to confirm our observations, and the mean angiographic fol- low-up time is not long enough to justify the real morphologic change of FAs after GKS. Second, some patients did not undergo rotational DSA, and all patients lacked microcatheter angiography. These factors may lead to underestimating the true incidence of FAs, particularly distal FAs, because of superimposition on BAVMs.

\section{CONCLUSIONS}

Distal FAs tend to shrink more frequently due to occlusion or normalization of angiographic features of distal feeders after BAVM obliteration by GKS. By contrast, proximal FAs shrink less frequently after BAVM obliteration. Spontaneous thrombosis of smaller FAs is more frequent than in larger FAs. The natural history and bleeding risk of unruptured FAs in those peritherapeutically managed by GKS were similar to those of asymptomatic intradural aneurysms in our study.

Disclosures: All authors declare that there are no conflict of interest related to the subject matter or material discussed in this article.

\section{REFERENCES}

1. Brown RD Jr, Wiebers DO, Forbes GS. Unruptured intracranial aneurysms and arteriovenous malformations: frequency of intracranial hemorrhage and relationship of lesions. J Neurosurg 1990;73: 859-63 Medline

2. Redekop G, TerBrugge K, Montanera W, et al. Arterial aneurysms associated with cerebral arteriovenous malformations: classification, incidence, and risk of hemorrhage. J Neurosurg 1998;89: 539-46 Medline

3. Berenstein A, Lasjaunias P. Classification of brain arteriovenous malformation. In: Berenstein A, Lasjaunias P, eds. Surgical Neuroangiography: Endovascular Treatment of Cerebral Lesion. Vol 4. Berlin: Springer-Verlag; 1992:48-55

4. Lv X, Wu Z, He H, et al. Proposal of classification of aneurysms coexisting with AVM and possible treatment strategies. Turk Neurosurg 2016;26:229-33 CrossRef Medline

5. Flores BC, Klinger DR, Rickert KL, et al. Management of intracranial aneurysms associated with arteriovenous malformations. Neurosurg Focus 2014;37:E11 CrossRef Medline

6. Kano H, Kondziolka D, Flickinger JC, et al. Aneurysms increase the risk of rebleeding after stereotactic radiosurgery for hemorrhagic arteriovenous malformations. Stroke 2012;43:2586-91 CrossRef Medline

7. Nataf F, Ghossoub M, Schlienger M, et al. Bleeding after radiosurgery for cerebral arteriovenous malformations. Neurosurgery 2004; 55:298-306; discussion 305-06 CrossRef Medline

8. Eliava S, Dmitriev A, Shekhtman O, et al. Treatment of brain arteriovenous malformations with hemodynamic aneurysms: a series of 131 consecutive cases. World Neurosurg 2018;110:e917-27 CrossRef Medline

9. Morgan MK, Alsahli K, Wiedmann M, et al. Factors associated with proximal intracranial aneurysms to brain arteriovenous malformations: a prospective cohort study. Neurosurgery 2016; 78:787-92 CrossRef Medline

10. Yang WY, Luo CB, Tsuei YS, et al. A single-institution study of predisposing factors of patients with BAVMs to flow-related aneurysm. J Formos Med Assoc 2019;118:707-12 CrossRef Medline

11. Lv X, Li Y, Yang X, et al. Characteristics of arteriovenous malformations associated with cerebral aneurysms. World Neurosurg 2011;76: 288-91 CrossRef Medline

12. Halim AX, Singh V, Johnstone C, et al; UCSF BAVM Study Project. Brain Arteriovenous Malformation. Characteristics of brain arteriovenous malformations with coexisting aneurysm: a comparison of two referral centers. Stroke 2002;33:675-79 CrossRef Medline 
13. Batjer H, Suss R, Samson D. Intracranial arteriovenous malformations associated with aneurysms. Neurosurgery 1986;18:29-35 CrossRef Medline

14. Meisel HJ, Mansmann U, Alvarez H, et al. Cerebral arteriovenous malformations and associated aneurysms: analysis of 305 cases from a series of 662 patients. Neurosurgery 2000;46:793-800; discussion 800-02 Medline

15. Chmayssani M, Rebeiz JG, Rebeiz TJ, et al. Relationship of growth to aneurysm rupture in asymptomatic aneurysms $\leq 7 \mathrm{~mm}$ : a systematic analysis of the literature. Neurosurgery 2011;68:1146-71; discussion 1171 CrossRef Medline

16. Cagnazzo F, Brinjikji W, Lanzino G. Arterial aneurysms associated with arteriovenous malformations of the brain: classification, incidence, risk of hemorrhage, and treatment-a systematic review. Acta Neurochir (Wien) 2016;158:2059-104 CrossRef Medline

17. Turjman F, Massoud TF, Viñuela F, et al. Aneurysm related to cerebral arteriovenous malformations: superselective angiographic assessment in 58 patients. AJNR Am J Neuroradiol 1994;15:1601-05 Medline

18. Rammos SK, Gardenghi B, Bortolotti C, et al. Aneurysms associated with brain arteriovenous malformations. AJNR Am J Neuroradiol 2016;37:1966-71 CrossRef Medline

19. Wong SC, Nawawi O, Ramli N, et al. Benefits of 3D rotational DSA compared with 2D DSA in the evaluation of intracranial aneurysm. Acad Radiol 2012;19:701-07 CrossRef Medline
20. van Rooij WJ, Sprengers ME, de Gast AN, et al. 3D rotational angiography: the new gold standard in the detection of additional intracranial aneurysms. AJNR Am J Neuroradiol 2008;29:976-79 CrossRef Medline

21. Shi WY, Li YD, Li MH, et al. 3D rotational angiography with volume rendering: the utility in the detection of intracranial aneurysms. Neurol India 2010;58:908-13 CrossRef Medline

22. Stapf C, Mohr JP, Pile-Spellman J, et al. Concurrent arterial aneurysms in brain arteriovenous malformations with haemorrhagic presentation. J Neurol Neurosurg Psychiatry 2002;73: 294-98 CrossRef Medline

23. Luo CB, Chen YL, Hsu SW, et al. Spontaneous healing and complete disappearance of a giant basilar tip aneurysm in a child. Interv Neuroradiol 2001;7:141-45 CrossRef Medline

24. Chung WY, Shiau CY, Wu HM, et al. Staged radiosurgery for extralarge cerebral arteriovenous malformations: method, implementation, and results. J Neurosurg 2008;109:65-72 Medline

25. International Study of Unruptured Intracranial Aneurysms Investigators. Unruptured intracranial aneurysms: risk of rupture and risks of surgical intervention. N Engl J Med 1998;339:1725-33 CrossRef Medline

26. Elhammandy MS, Aziz-Sultan MA, Heros RC. The management of cerebral arteriovenous malformations associated with aneurysms. World Neurosurg 2013;80;e123-29 CrossRef Medline 